\title{
Which Comes First: Consciousness or Aspartate Receptors?
}

\author{
Igor Kungurtsev, M.D. \\ California Institute of Integral Studies, \\ San Francisco, CA
}

ABSTRACT. This paper is a critique of Karl Jansen's hypothesis that neardeath and ketamine experiences are caused by blockade of N-methyl-Daspartate receptors. An assumption that consciousness and its alterations are merely the product of neuronal activity is only one of many possible beliefs about reality. An alternative, which can be verified through one's own direct experience, is that consciousness is always a subject and body is only its object. The objects come and go; consciousness remains.

Near-death studies is a field where different disciplines must necessarily cooperate. The relevant disciplines here include not only medicine and neurosciences but also religion, philosophy, and transpersonal psychology. In this context, attempts to reduce an explanation of the near-death experience (NDE) to mere interactions of neuroreceptors look especially archaic. Karl Jansen's article is certainly an example of such biological reductionism.

Jansen's article began with the assertion on simple logical grounds that NDEs are not evidence for life after death: death is defined as the final irreversible end. Now who is the authority to define death as the final end? It happens to be the Oxford English Dictionary! Jansen quoted it to support his assertion, tacitly assuming that the reader has the same faith in the final authority of the Oxford English

Igor Kungurtsev, M.D., was formerly a psychiatrist at the Bekhterev Psychoneurological Research Institute in St. Petersburg, Russia, where he participated in pioneering research into death-rebirth therapy with ketamine. He currently teaches philosophy and religion at the California Institute of Integral Studies in San Francisco, $\mathrm{CA}$, and at John F. Kennedy University in Orinda, CA. Reprint requests should be addressed to Dr. Kungurtsev at P. O. Box 7009-157, Lafayette, CA 94549. 
Dictionary as he does. On a planet where billions of people believe in reincarnation or some form of life after death, the Oxford English Dictionary holds the authority in such questions as death for rather a minority. This should be taken into consideration when "simple logical grounds" need to be established.

But since Jansen's paper is a scientific one, let us put beliefs and faiths aside, and address the experience. For whom is death "the final end"? It is the external observer only who witnesses the "final cessation of vital functions" of the body, but what is the inner experience of the one whose body becomes a corpse? The main problem with the "objectively scientific" study of consciousness is that it always overlooks the simple experiential fact that consciousness can not be objectified. In other words, consciousness is always a subject, and never an object. It is only when consciousness is mixed with an object, such as the body, that the confusion arises.

Even in common language we say "my body." We don't say "I-body" or "me-body." Everyone can see through his or her own direct experience that one is aware of one's body. In other words, the body is the object of one's awareness. This is a simple experiential fact. Now, when the physical body ceases to be the object of one's awareness, this awareness simply continues to be conscious of other objects, and that's what happens in death, in the NDE, in the ketamine experience, and in deep meditation. Basically, this fact-that you are consciousness and your body is just one of the objects of your awareness-can be realized without an NDE or a psychedelic experience. But just as our eyes cannot see themselves, similarly we always overlook that very consciousness through which we are aware of everything.

For many people in the West this realization-that I can exist without the body-happens through such dramatic events as an NDE or psychedelic experience. Having done extensive research with ketamine, I agree with Jansen that ketamine is a unique substance whose action models the NDE much more than any other known psychedelic drug. With sufficient doses, the conviction that one has died is quite common in ketamine experiences. The sense of being completely disembodied, as well as the intensity of the perceived reality of another realm, leaves no doubt that all this is actually happening.

The acknowledgment that ketamine amazingly models the NDE is the only common point that I share with Jansen. The focus of his paper was to suggest that both NDEs and ketamine experiences are 
caused by blockade of $\mathrm{N}$-methyl-D-aspartate (NMDA) receptors. This brings us back to the basic neurological assumption-which is only one of many beliefs about reality-that consciousness is the product of neuronal activity.

Now, who studies NMDA receptors? It is scientists in whose consciousness all these ideas play. If those scientists were not conscious in the first place, who would be speaking about NMDA receptors? So, the truth is the other way around. It is not neurons that produce consciousness; it is consciousness that infuses brain with sentiency and makes neurons work. When consciousness departs, what remains is dead matter.

A few lucky ones will realize spontaneously or with the help of the right teacher that they are immortal consciousness and not a mortal body. Others become convinced of this fact after an NDE or ketamine experience. And those who firmly believe that consciousness is the product of matter perhaps have to wait until the moment of their own death to realize that which is experientially obvious even now. 